\title{
Remote Sensing Monitoring and Driving Force Analysis of Salinized Soil in Grassland Mining Area
}

\author{
Zhenhua Wu ${ }^{1,2,3}$, Mingliang Che ${ }^{4}$, Shutao Zhang ${ }^{5}$, Linghua Duo ${ }^{6}$, Shaogang Lei ${ }^{2, *}$, Qingqing Lu ${ }^{7, *}$ \\ and Qingwu Yan ${ }^{3, *}$
}

check for updates

Citation: Wu, Z.; Che, M.; Zhang, S.; Duo, L.; Lei, S.; Lu, Q.; Yan, Q. Remote Sensing Monitoring and Driving Force Analysis of Salinized Soil in Grassland Mining Area. Sustainability 2022, 14, 741. https:// doi.org/10.3390/su14020741

Academic Editor: Salvador García-Ayllón Veintimilla

Received: 27 November 2021 Accepted: 6 January 2022

Published: 10 January 2022

Publisher's Note: MDPI stays neutral with regard to jurisdictional claims in published maps and institutional affiliations.

Copyright: (C) 2022 by the authors. Licensee MDPI, Basel, Switzerland. This article is an open access article distributed under the terms and conditions of the Creative Commons Attribution (CC BY) license (https:// creativecommons.org/licenses/by/ $4.0 /)$.
1 School of Economics and Management, China University of Mining and Technology, Xuzhou 221116, China; wuzhenhua@cumt.edu.cn

2 Engineering Research Center of Ministry of Education for Mine Ecological Restoration, China University of Mining and Technology, Xuzhou 221116, China

3 School of Public Policy \& Management, China University of Mining and Technology, Xuzhou 221116, China

4 School of Geographic Science, Nantong University, Nantong 226019, China; dawnche@163.com

5 Jiangsu Energy Sumeng Branch Office of Xuzhou Coal Mining Group, Xilinhot 026021, China; ghbzst@126.com

6 Faculty of Geomatics, East China University of Technology, Nanchang 330013, China; dlh_123@ecut.edu.cn

7 College of Environmental Engineering, Xuzhou University of Technology, Xuzhou 221018, China

* Correspondence: lsgang@cumt.edu.cn (S.L.); luluqingzi@163.com (Q.L.); yanqingwu@cumt.edu.cn (Q.Y.)

\begin{abstract}
To deal with the problem of soil salinization that exists widely in semi-arid grassland, the Shengli Coalfield in Xilinhot City was selected as the study area. Six periods of Landsat remote sensing data in 2002, 2005, 2008, 2011, 2014, and 2017 were used to extract the salinity index (SI) and surface albedo to construct the SI-Albedo feature space. The salinization monitoring index (SMI) was used to calculate and classify the soil salinization grades in the study area. The soil salinization status and its dynamic changes were monitored and analyzed. Combined with the logistic regression model, the roles of human and natural factors in the development of soil salinization were determined. The results were as follows: (1) The SMI index constructed using the SI-Albedo feature space is simple and easy to calculate, which is conducive to remote sensing monitoring of salinized soil. $\mathrm{R}^{2}$ of the SMI and soil salt content in the 2017 data from the study area is 0.7313 , which achieves good results in the quantitative analysis and monitoring of soil salinization in the Xilinhot Shengli Coalfield. (2) The study area is a grassland landscape. However, grassland landscapes are decreasing year by year, and town landscapes, mining landscapes, and road landscapes are greatly increased. The areas of soil salinization reversion in the Shengli mining area from 2002-2005, 2005-2008, 2008-2011, 2011-2014, 2014-2017, and 2002-2017 were $65.64 \mathrm{~km}^{2}, 1.03 \mathrm{~km}^{2}, 18.44 \mathrm{~km}^{2}, 0.9 \mathrm{~km}^{2}, 7.52 \mathrm{~km}^{2}$, and $62.33 \mathrm{~km}^{2}$, respectively. The overall trend of soil salinization in the study area was reversed from 2002 to 2017 . (3) The driving factors of salinized land from 2002 to 2008 are as follows: the distance to the nearest town landscape $>$ the distance to the nearest mining landscape $>$ the distance to the nearest road landscape. The driving factors of salinized land from 2008 to 2017 are as follows: the distance to nearest mining landscape $>$ the distance to the nearest water landscape $>$ the distance to nearest town landscape $>$ altitude $>$ aspect. Coal exploitation and town expansion have occupied a large amount of saline land, and petroleum exploitation and abandoned railway test sites have intensified the development of saline land. This study provides a reference for the treatment and protection of soil salinization in semi-arid grassland mining areas.
\end{abstract}

Keywords: grassland mining area; SI-Albedo feature space; soil salinization remote sensing monitoring; driving force analysis

\section{Introduction}

Soil salinization is one of the main causes of soil degradation. Soil salinization usually occurs in arid and semi-arid regions with high evaporation intensity, high groundwater 
levels, and more soluble salts. Soil salinization causes serious deterioration of the regional ecological environment, reduces crop growth rate, and leads to a serious decline in crop yield. Soil salinization is one of the main barriers to the development of the Inner Mongolia Grassland [1]. Therefore, it is necessary to monitor the degree of soil salinization in real-time [2]. Regional soil salinity mapping is helpful for decision-makers when making improvements and optimization policies for establishing and specifying potential soil salinization areas in order to avoid unreasonable allocation of regional water and soil resources and sustainable degradation of the land ecosystem in arid and semi-arid regions [3]. Although the traditional monitoring and mapping method has high precision, field sampling is time-consuming and laborious, and the field variability of soil properties is large. Limited by staffing and material resources, it is often difficult to collect enough samples. The soil salt information obtained is generally rough, and the results obtained are not representative [4]. Remote sensing technology has the advantage of gathering a large amount of information and being large scale, wide-ranging, timely, low cost, and less restricted by ground conditions [3]. Real-time monitoring of the temporal and spatial dynamics of soil salinization is essential for salinization prevention, ecological protection, and regional sustainable development [5].

Advanced quantitative remote sensing monitoring research uses all kinds of indicators extracted from multispectral remote sensing images to construct feature spaces for surface information extraction and dynamic monitoring [6]. Selecting suitable feature parameters to establish feature space for improving the accuracy of quantitative remote sensing monitoring is an innovative topic in current research [7]. Fei Wang put forward the concept of NDVI-SI feature space and established the remote sensing monitoring index model of soil salinization [8]. Jianli Ding constructed MSAVI-WI two-dimensional feature space to monitor soil salinization of an oasis in an arid region [7]. Tianyou Zhang proposed the concept of MSAVI-SI feature space and then constructed the index model of salinization remote sensing information extraction [9]. Based on the method of SI (salinization index)brightness feature space, Zhenhua Wu et al. constructed a new spectral index named the semi-arid steppe salinization index (SASSI), which is more suitable for soil salinization remote sensing monitoring in semi-arid steppes [10]. Xueping Ha found that the spatial distribution of SI-Albedo feature space has a significant law, that is, the non-salinized soil is in mass distribution, which can extract the information of salinized soil quantitatively and quickly. A soil salinization remote sensing monitoring index (SMI) based on spectral feature space was established [11]. Beyond soil salinization remote sensing monitoring [12], the feature space method has been widely used in desertification remote sensing monitoring $[13,14]$, drought remote sensing monitoring [15,16], remote sensing monitoring of soil dryness and wetness [17], heavy metal stress evaluation [18], crop moisture estimation [19], cultivated land fertility [20], surface evapotranspiration [21], soil moisture retrieval [22,23], and many other remote sensing, quantitative monitoring fields.

The Xilinguole Grassland is located in the Central Asia sub-region of the Eurasian grassland area, and it is the core part of the Eurasian temperate grassland. The Xilinguole Grassland is located in the transitional zone from forest to desert grassland and is the core area of the north sand control zone in the "two screens and three belts" policy of China's ecological security. The Xilinguole Grassland is famous for its complete grassland type and has maintained a continuous distribution of complete natural grassland vegetation, including meadow grassland, typical grassland, desert grassland, and sandy vegetation. The Xilinguole Grassland is a precious treasure trove of grassland biodiversity, which provides abundant genetic resources for human beings and has important research value in China and the world [24-26]. The Xilinguole Grassland is one of four natural grasslands in China and the only national grassland nature reserve listed in the UN human and biosphere protection network [27,28]. However, due to climate change, human activities, and other reasons, since the 1970s, the Xilinguole Grassland has begun to degenerate. So far, the salinization area accounts for four percent of the grassland area, which has a serious impact on the local herdsmens' living standards and regional economic development and has 
become one of the most direct threats to the ecological security of northern China [29]. Similarly, the Shengli coalfield in Xilinhot is located in the hinterland of the Xilinguole Grassland. It is a typical mining city that exploits various mineral resources such as coal, oil, and heavy metal at the same time. The contradiction between humans, land, and the ecological environment is serious.

Based on Landsat TM and OLI images of the Shengli large-scale coal base in Xilinhot taken in 2002, 2005, 2008,2011, 2014, and 2017, this paper studied the temporal and spatial development and change law of salinization and its driving factors over the past 15 years by using the salinization monitoring index (SMI). It provides the reference and basis for regional salinization remote sensing monitoring, ecological environment protection, and the sustainable development of Shengli's large-scale coal base in Xilinhot.

\section{Materials and Methods}

\subsection{Overview of the Study Area}

The study area is the Shengli mining area in the northern suburb of Xilinhot City, Inner Mongolia Autonomous Region, China. The Shengli mining area is one of 14 largescale coal bases in East Mongolia. The geographical coordinates are $43^{\circ} 02^{\prime}-44^{\circ} 52^{\prime}$ north latitude, $115^{\circ} 18^{\prime}-117^{\circ} 06^{\prime}$ east longitude, and the altitude is $970-1202 \mathrm{~m}$. It is located in the mid-latitude westerly airflow zone, belonging to a mid-temperate, semi-arid continental climate, with annual average precipitation of $294.9 \mathrm{~mm}$ and a frost-free period of 110 days. Over the years, the extreme maximum temperature is $38.3^{\circ} \mathrm{C}$, the minimum temperature is $-42.4^{\circ} \mathrm{C}$, and the average temperature is $1.7^{\circ} \mathrm{C}$. The annual maximum rainfall is $481.0 \mathrm{~mm}$, the annual minimum rainfall is $146.7 \mathrm{~mm}$, the annual average rainfall is $294.74 \mathrm{~mm}$, and the annual average evaporation capacity is $1794.64 \mathrm{~mm}$. The Xilin River is the largest in the coalfield, with a total length of $268 \mathrm{~km}$, and has become a seasonal river. The mining area is in a northeast and southwest strip, with a strike length of $45 \mathrm{~km}$ and an average width of $7.6 \mathrm{~km}$ from north to south. The planned area of the mining area is about $423 \mathrm{~km}^{2}$, and the total amount of coal resources is about 22.4 billion tons. The mining area is divided into six open-pit coal mines. The oil field in the middle of the Shengli coalfield is subordinate to the Erlianhaote branch of the North China oil field of PetroChina, and the spatial distribution of each mine is shown in Figure 1.

\subsection{Data Source and Remote Sensing Image Preprocessing}

June to August is the rainy and vegetation growing season of the Xilinguole Grassland. Six Landsat images were downloaded from the U.S. Geological Survey website (Table 1). The data type before 2013 is Landsat TM, and the data type after 2013 is Landsat OLI (Operational Land Imager). ENVI (The Environment for Visualizing Images) software is used for radiation calibration, FLAASH atmospheric correction, image registration, image clipping, and other preprocessing work. The landscape type map adopts existing landscape ecological classification results [30-34].

$$
S I=\sqrt{\rho_{\text {Blue }} \times \rho_{\text {Red }}}
$$

Inversion of surface albedo: The surface albedo is the ratio of the solar radiation flux reflected by the earth's surface to the incident solar radiation flux, which represents the reflection ability of the earth's surface for solar radiation. Estimating surface albedo in the study area was determined using the inversion model of Landsat data established by Liang Shunlin. The "albedo" used in this paper is a broadband albedo [35].

$$
\text { Albedo }=0.356 \rho_{\text {Blue }}+0.130 \rho_{\text {Red }}+0.373 \rho_{\text {NIR }}+0.085 \rho_{\text {SWIR } 1}+0.072 \rho_{\text {SWIR2 }}-0.0018
$$

In the formula, $\rho_{\text {Blue }}, \rho_{\text {Red }}, \rho_{\text {NIR }}, \rho_{\text {SWIR1 }}$, and $\rho_{S W R 2}$ represent the blue band, red band, near-infrared band, short-wavelength infrared band, and short-wavelength infrared band, respectively. 


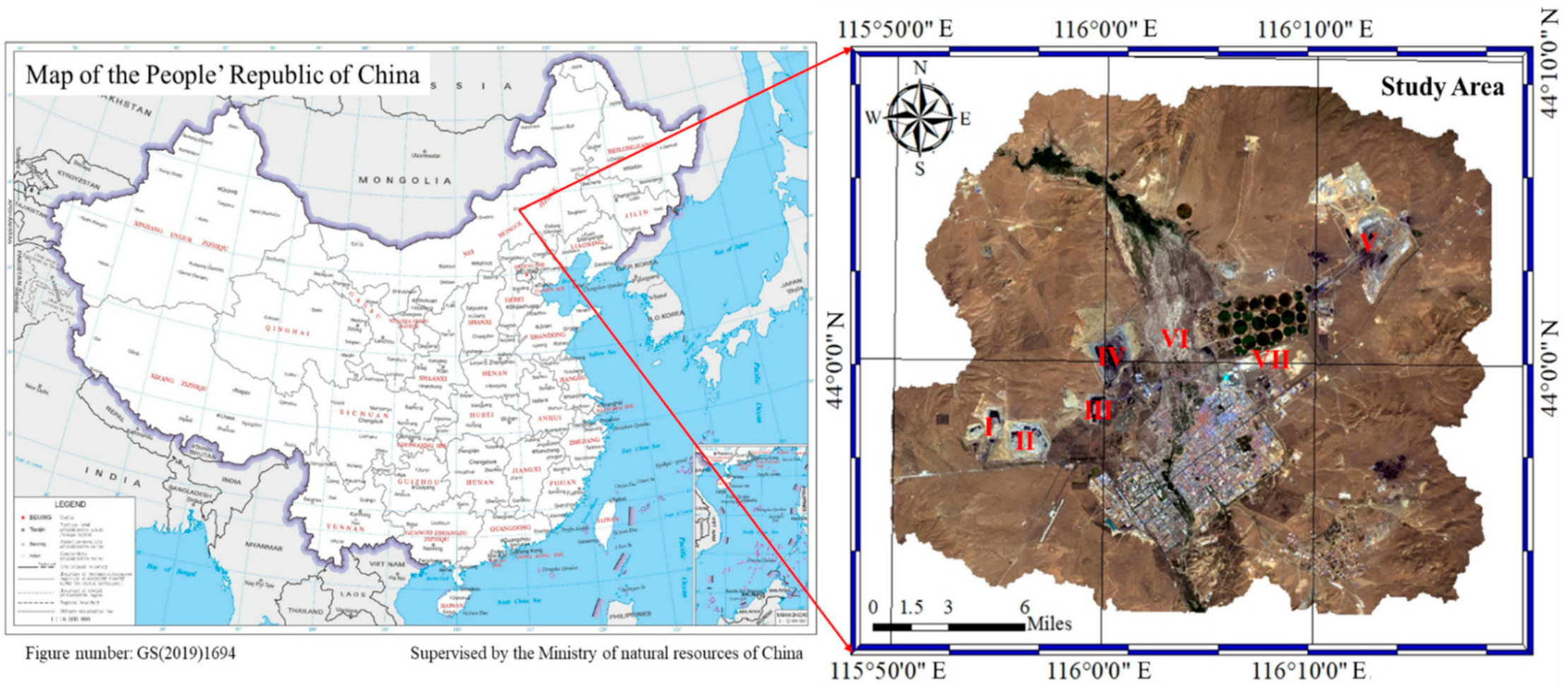

Figure 1. Location of the study area. I: Open-pit germanium mine; II: West No. 2 open-pit mine; III: West No. 3 open-pit mine; IV: No. 1 open-pit mine; V: East No. 2 open-pit mine; VI: Oil field; VII: Abandoned railway test sites. 
Table 1. Data source.

\begin{tabular}{cccc}
\hline Year & Number & Type & Resolution \\
\hline 8 July 2002 & LT51240292002189BJC00 & Landsat 5 & $30 \mathrm{~m}$ \\
17 August 2005 & LT51240292005229BJC02 & Landsat 5 & $30 \mathrm{~m}$ \\
8 July 2008 & LT51240292008190BJC00 & Landsat 5 & $30 \mathrm{~m}$ \\
2 August 2011 & LT51240292011214IKR00 & Landsat 5 & $30 \mathrm{~m}$ \\
25 July 2014 & LC81240292014206LGN00 & Landsat 8 & $30 \mathrm{~m}$ \\
17 July 2017 & LC81240292017198LGN00 & Landsat 8 & $30 \mathrm{~m}$ \\
\hline Calculation of Salinity Index (SI). & & &
\end{tabular}

\subsection{Construction of SI-Albedo Feature Space}

Khan's [36] study found that the red band of the Landsat image has sensitive response characteristics to soil salinity. Comparing the spectral characteristics of typical ground objects and a band mixing test found that the SI determined by red and blue bands of remote sensing images can better reflect the degree of soil salinization. Meanwhile, the albedo retrieved from remote sensing data is a biophysical parameter of the ratio of total reflected energy to the total incident energy of solar radiation in hemispherical space. With the decrease of vegetation coverage, the surface moisture and surface roughness decreased, and the surface albedo increased correspondingly. Under the condition of no irrigation, the near-surface soil moisture of salinized soil is greatly affected by groundwater. When the soil moisture is higher, the surface soil salt content is higher. Therefore, the albedo parameter can also reveal the soil salinization information [11].

According to the research of Verstraete [37] and Xueping Ha [11], there is a good linear correlation between the salinity index $(S I)$ and surface albedo corresponding to different salinized lands. Dividing the SI-Albedo feature space in the vertical direction representing the changing trend of salinization can effectively distinguish different salinized lands. The position of the vertical direction in SI-Albedo feature space can be expressed by a simple binary linear polynomial in SI-Albedo feature space:

$$
S M I=(S I+a \times \text { Albedo }) / \sqrt{a^{2}+1}
$$

where the $S M I$ is the remote sensing monitoring index of soil salinization, $S I$ is the salinity index, albedo is the surface albedo, and $a$ is obtained from Equation (4):

$$
\text { Albedo }=a \times S I+b
$$

where $a$ and $b$ are regression coefficients.

The salinization monitoring index (SMI) of each pixel can be calculated by Equation (3), and the salinization can be divided into different grades using this value. The spatial scatter diagram of the SI-Albedo feature space of each year is constructed, as shown in Figure 2.

\subsection{Model Applicability Verification and Salinization Classification}

In late July 2017, the authors sampled, tested, and analyzed the field soil samples in the study area, as shown in Figure 3. The results show that the SMI has good applicability in the study area. According to the national standard of The People's Republic of China "Grading standard for degradation, desertification and salinization of natural grassland (GB 19377-2003)" and SI-Albedo feature space, the SMI values of different salinized soils were determined: non-salinization $(<0.3)$, mild salinization $(0.3-0.32)$, moderate salinization $(0.32-0.34)$, and severe salinization $(>0.34)$. 


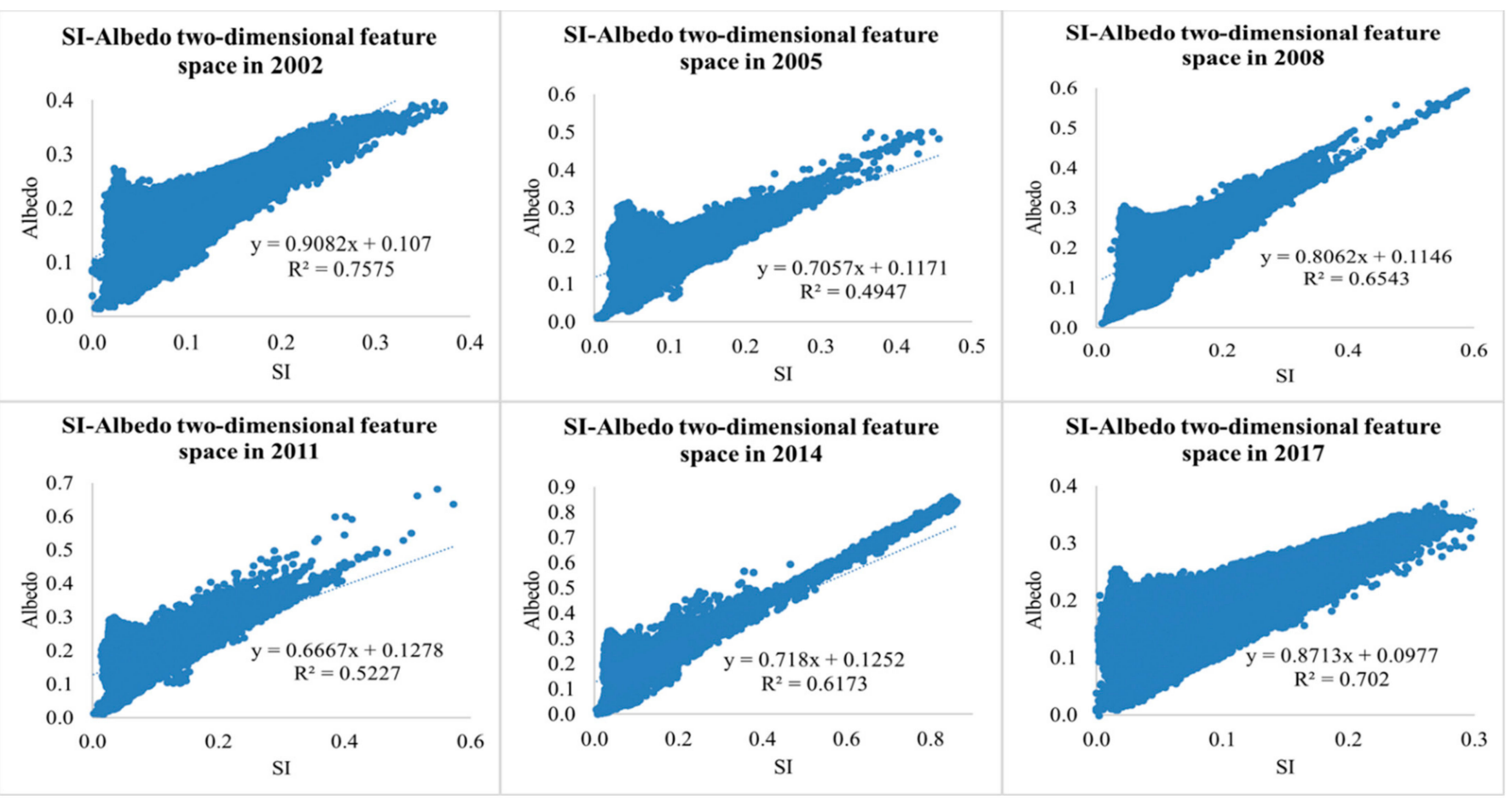

Figure 2. SI-Albedo two-dimensional feature space of the study area.

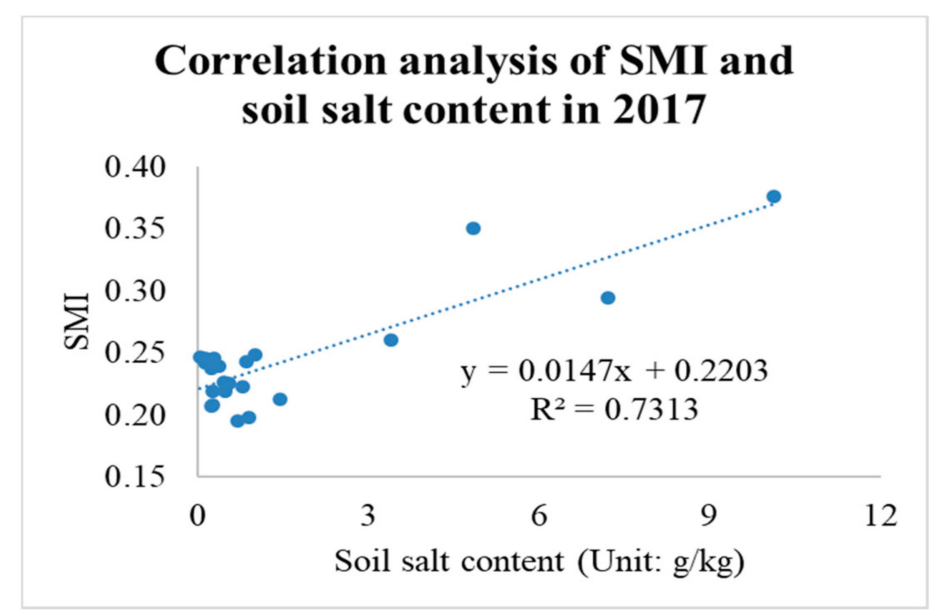

Figure 3. Correlation analysis of SMI and soil salt content in 2017.

\subsection{Comparative Analysis of Salinization Changes}

To reflect the dynamic change of the salinization of land over time, the index of salinization change speed was introduced. The dynamic change rate of soil salinization was used to reflect the change rate of soil salinization in the study period:

$$
K=\frac{U_{b}-U_{a}}{U_{a}} \times \frac{1}{T} \times 100 \%
$$

where $K$ is the change rate of a certain degree of salinization in the study period; $U_{a}$ and $U_{b}$ are the areas of certain salinized land at the beginning and end of the study, respectively; and $T$ is the study period. 


\subsection{Logistic Regression Model \\ 2.6.1. Model and Method}

The soil salinization variable is binary, where 1 means that the land in the study area is salinized, and 0 means that the land is not salinized. Based on sampling data, the binary logistic regression model generates regression coefficients for each variable and discusses the relationship between the independent variable and the dependent variable in the model through these coefficients. If $p$ is the probability of occurrence of an event, and the value range is $0-1$, then $1-p$ is the probability that the event does not occur. This probability can be calculated by the logistic function [38].

\subsubsection{Selection and Treatment of Variables}

\section{(1) Dependent variable}

According to the analysis of landscape pattern change and landscape pattern transfer matrix structure, it can be seen that the restoration of salinized land in the study area is manifested in the transformation from salinized land to a town landscape, grassland landscape, and mining landscape. The spatial distribution simulation of the study is divided into two periods: 2002-2008 and 2008-2017. Logistic regression analysis was conducted for the study area, and the dependent variable types are shown in Table 2.

\section{(2) Independent variable}

The factors affecting the change of the landscape pattern are complex and multicollinear. Based on the aforementioned theoretical analysis, natural factors and spatial distance were selected for analysis. According to the availability of data, 10 factors closely related to land-use change were selected: altitude, slope, aspect, distance to the nearest mining landscape, distance to the nearest town center, distance to the water area, and distance to the nearest road landscape (Table 2). The DEM with $30 \mathrm{~m}$ spatial resolution was downloaded from the geospatial data cloud. The altitude, slope, and aspect are extracted from the DEM image through the spatial analysis module of ArcGIS software. According to "Technical Regulations for Determining Cultivated Land Slope Grading Using DEM", the slope is divided into five grades: first grade $\left(0-2^{\circ}\right)$, second grade $\left(2-6^{\circ}\right)$, third grade $\left(6-15^{\circ}\right)$, fourth grade $\left(15-25^{\circ}\right)$, and fifth grade $\left(>25^{\circ}\right)$. The slope aspect data are divided into nine types: plane $\left(-1^{\circ}\right)$, northeast slope $\left(22.5-67.5^{\circ}\right)$, east slope $\left(67.5-112.5^{\circ}\right)$, southeast slope $\left(112.5-157.5^{\circ}\right)$, south slope $\left(112.5-157.5^{\circ}\right)$, southwest slope $\left(202.5-247.5^{\circ}\right)$, west slope $\left(247.5-292.5^{\circ}\right)$, northwest slope $\left(292.5-337.5^{\circ}\right)$, and north slope $\left(0-22.5^{\circ}\right.$ and $\left.337.5-360^{\circ}\right)$. The spatial distance factor is generated by the buffer Wizard tool.

Table 2. Influencing factors of soil salinization in the Shengli mining area.

\begin{tabular}{|c|c|c|c|}
\hline Variable & Data Layer & Grid Style & Unit/Description \\
\hline \multirow{2}{*}{ Dependent Variable } & Soil salinization (2002-2008) & Dichotomous & $0-1$ \\
\hline & Soil salinization (2008-2017) & Dichotomous & $0-1$ \\
\hline \multirow{7}{*}{ Independent variable } & Distance to nearest town landscape & Continuous type & $\mathrm{m}$ \\
\hline & Distance to nearest mining landscape & Continuous type & $\mathrm{m}$ \\
\hline & Distance to the nearest road landscape & Continuous type & $\mathrm{m}$ \\
\hline & Distance to the nearest water landscape & Continuous type & $\mathrm{m}$ \\
\hline & Aspect & Multi-classification & $1-9$ \\
\hline & Slope & Multi-classification & $1-5$ \\
\hline & Altitude & Continuous type & $\mathrm{m}$ \\
\hline
\end{tabular}

\subsubsection{Sampling Process}

The results of the logistic regression model are different when different samples are selected, making it necessary to use enough samples to avoid the spatial autocorrelation 
between sampling points. With the help of ArcGIS random sampling mode, 10,000 sample points evenly distributed in the whole study area were selected. Through numerical matching, 2000 sample points were selected to participate in the calculation, and the values of the independent variable and dependent variable were obtained using the sample points, which provided the data for the regression model.

\subsubsection{Collinearity Diagnosis of Independent Variables}

Like other multiple linear regression models, the logistic regression model is more sensitive to the collinearity of the independent variables. Therefore, it is necessary to diagnose the multiple collinearities of the independent variables before analyzing the binary logistic regression model. This study uses the tolerance $(\mathrm{T})$ indicator for testing. Generally speaking, a tolerance $<0.2$ can be regarded as the standard for the existence of multiple collinearities. If the tolerance of an independent variable is less than 0.1 , the collinearity is very serious.

\subsubsection{Model Checking}

To better analyze the impact of each independent variable on land-use change, it is necessary to test whether the predicted value of the model is consistent with the corresponding observation value. The $H L$ test is usually used for logistic regression with more independent variables or continuous variables. In the model, the $H L$ value is not significant, indicating that the model fits well; however, the statistically significant $H L$ value indicates that the model does not fit well $[39,40]$. This model introduces continuous variables, has many independent variables, and has a large sample size, so the $H L$ index is used as the goodness-of-fit index.

\section{Results and Discussion}

\subsection{Spatial and Temporal Variation of Soil Salinization}

Examining Figures 1 and 4 and Table 3, it can be seen that salinized land is mainly distributed in salt marsh wetlands and their surrounding areas. In areas with frequent human activity, the overall trend of salinization has improved over the past 15 years. More salinized areas have been restored from 2002 to 2005, the area of salinized soil has changed slightly from 2005 to 2017 , and the ecological status is relatively stable.

From 2002 to 2017, grassland landscape accounted for the largest proportion of all landscape types in the Shengli mining area of Xilinhot City, all above $74 \%$, indicating that the study area is a typical grassland-based landscape type. However, the area of grassland landscape shows a decreasing trend year by year. The mining landscape is increasing year by year. The proportion of town landscape increased year by year, from $5.7 \%$ in 2002 to $13.04 \%$ in 2017, with a net increase of $75.04 \mathrm{~km}^{2}$. The drought in the study area is serious, and the water landscape has been below $0.06 \%$ over the years, demonstrating an increasing trend.

According to the land-use change transfer matrix (Table 4), the area of salinized land decreased from $66.36 \mathrm{~km}^{2}$ in 2002 to $21.12 \mathrm{~km}^{2}$ in 2017 , with an overall reduction of $68.17 \%$; among these areas, salinized land was turned into a mining landscape of $0.58 \mathrm{~km}^{2}$, while $95.17 \%$ of the mining landscape occupied the grassland landscape. The damage caused by coal mining to grassland mainly manifested from digging and occupying grassland. The salinized land turned into a town landscape of $9.37 \mathrm{~km}^{2}$, mainly due to the town's expansion; the salt marsh wetland in the southwest of the city turned into town construction land; and the salinized land turned into a road landscape of $1.81 \mathrm{~km}^{2}$ and was restored to a grassland landscape of $33.45 \mathrm{~km}^{2}$. 


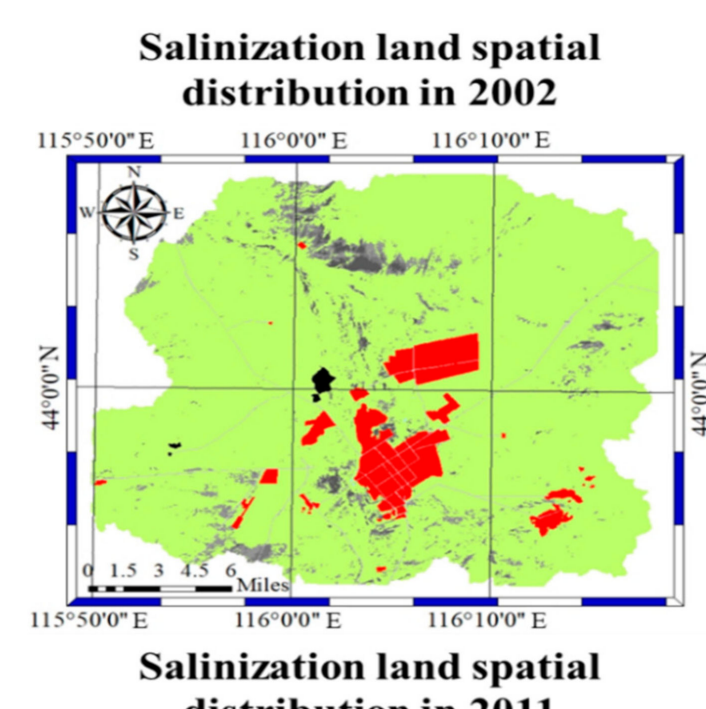

\section{Salinization land spatial distribution in 2005}

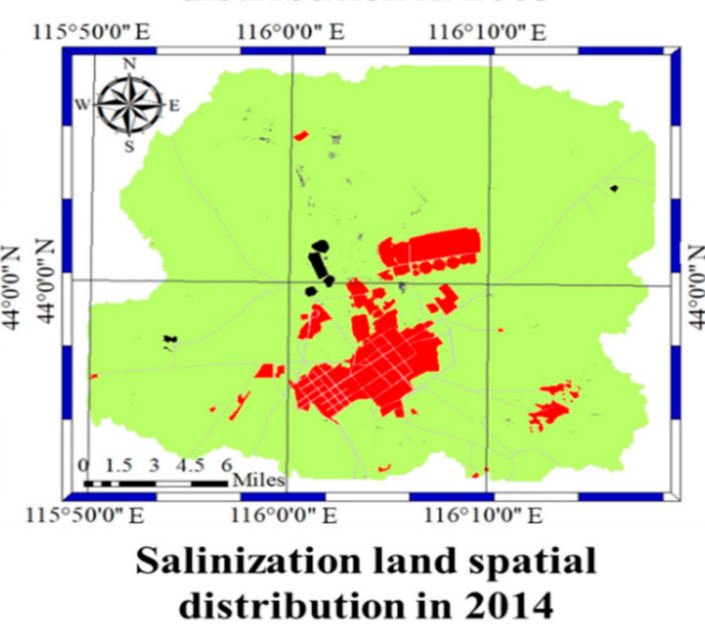

Salinization land spatial distribution in 2008

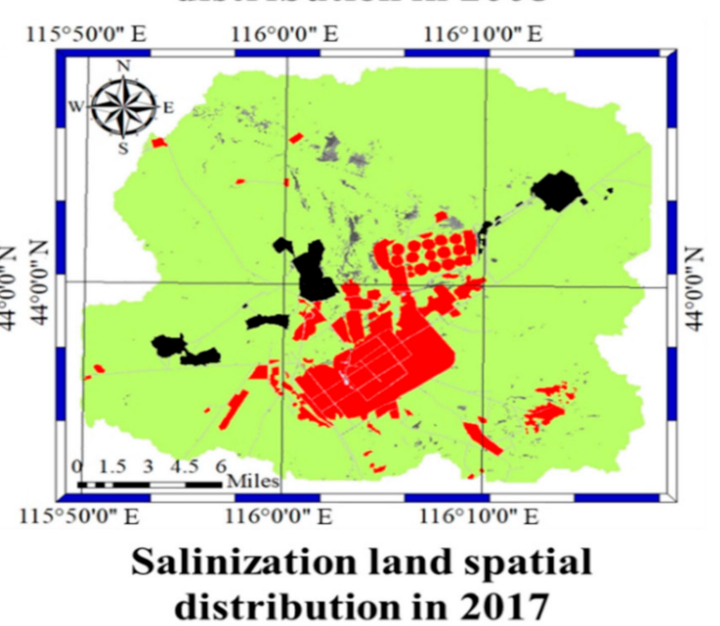

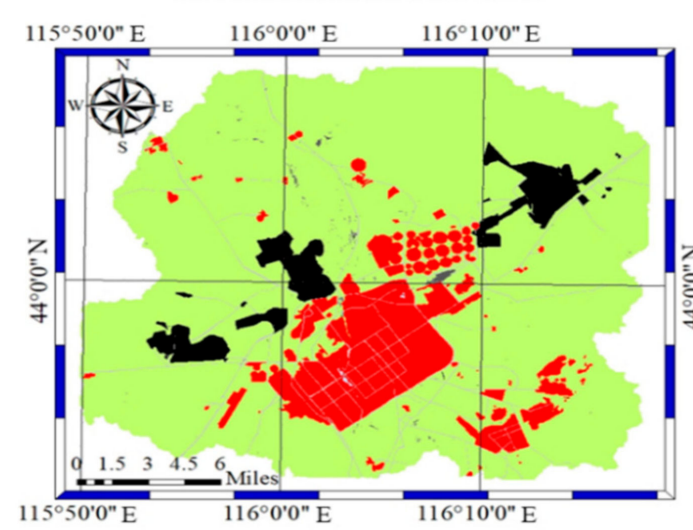

Legend:
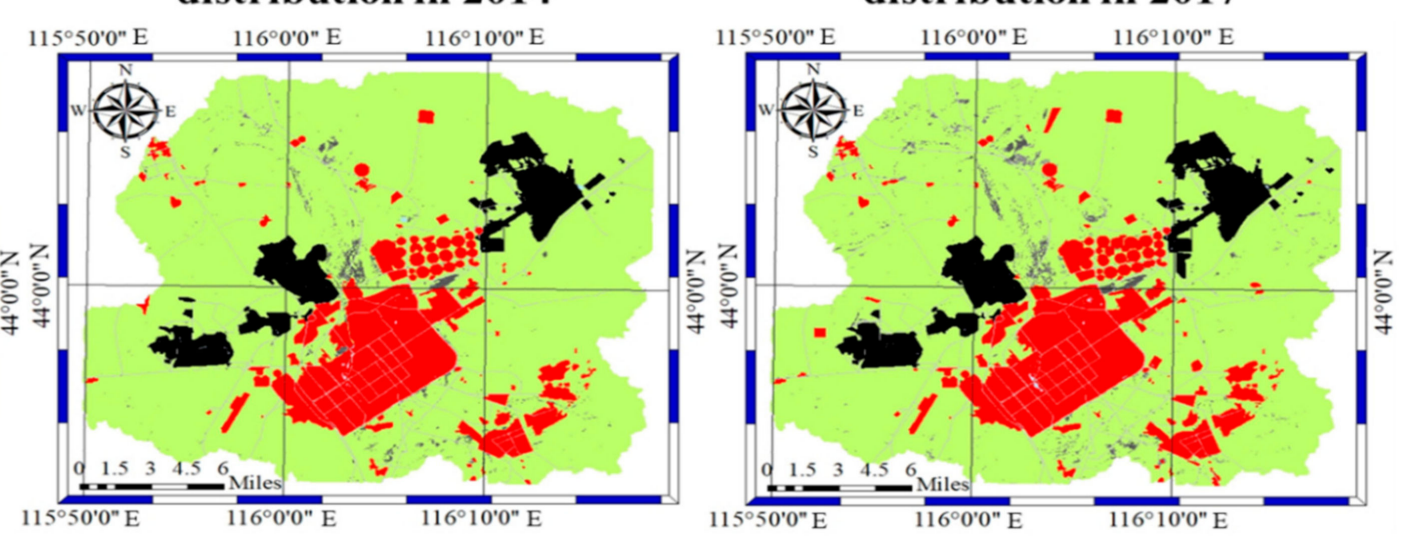

Town Landscape $\square$ Grassland Landscape

Water Landscape

Mining Landscape

Severe Salinization

Moderate Salinization

Mild Salinization

Figure 4. Salinization land spatial distribution in different periods. 
Table 3. Area statistics of various landscape types (Area $/ \mathrm{km}^{2}$; Percentage $\left./ \%\right)$.

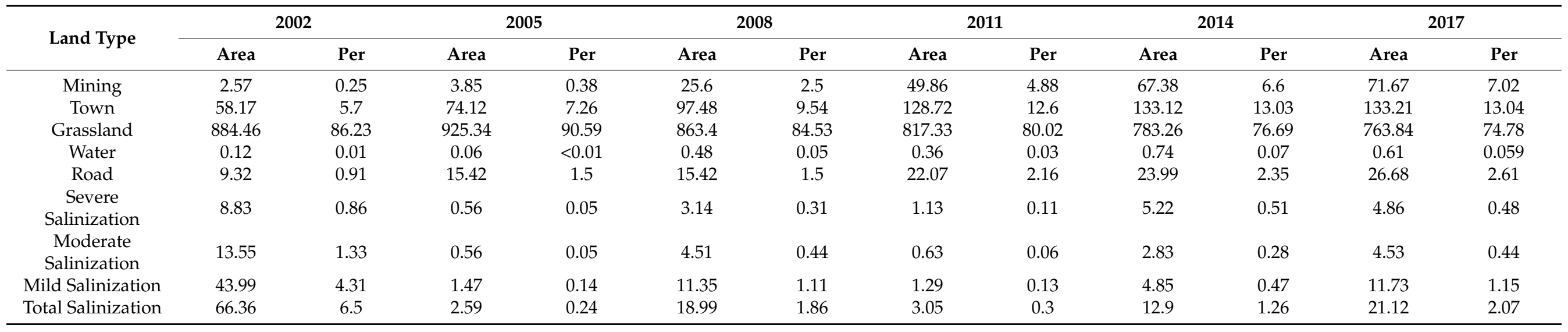

Table 4. Landscape pattern transfer matrix of the study area from 2002 to $2017\left(\mathrm{~km}^{2}\right)$.

\begin{tabular}{|c|c|c|c|c|c|c|c|c|}
\hline Land Type & Mining & Town & Grassland & Water & Road & Severe Salinization & $\begin{array}{c}\text { Moderate } \\
\text { Salinization }\end{array}$ & Mild Salinization \\
\hline Mining & 2.54 & 0.05 & 68.22 & 0.29 & 0.00 & 0.06 & 0.06 & 0.46 \\
\hline Town & 0.01 & 52.29 & 74.41 & 1.00 & 0.06 & 2.29 & 2.18 & 5.27 \\
\hline Grassland & 0.01 & 4.71 & 710.15 & 1.21 & 0.01 & 3.86 & 9.37 & 34.09 \\
\hline Water & 0.00 & 0.76 & 17.30 & 6.80 & 0.00 & 0.12 & 0.31 & 1.39 \\
\hline Road & 0.00 & 0.00 & 0.51 & 0.00 & 0.05 & 0.00 & 0.01 & 0.03 \\
\hline Severe Salinization & 0.00 & 0.06 & 3.34 & 0.00 & 0.00 & 0.61 & 0.30 & 0.55 \\
\hline $\begin{array}{l}\text { Moderate } \\
\text { Salinization }\end{array}$ & 0.00 & 0.08 & 2.93 & 0.00 & 0.00 & 0.59 & 0.37 & 0.56 \\
\hline Mild Salinization & 0.00 & 0.22 & 7.60 & 0.00 & 0.00 & 1.30 & 0.95 & 1.65 \\
\hline
\end{tabular}


According to the analysis results of the single land use dynamic degree in Table 5, the average annual recovery rate of salinization was higher in 2002-2005, and the recovery rate of severe, moderate, and mild salinization land reached $-31.22,-31.96$, and -32.22 , respectively. From 2008 to 2017, the overall situation of salinized land was relatively stable, and the growth rate of severely salinized land was relatively fast. It is worth noting that the mining landscape, town landscape, and road landscape have been expanding rapidly, especially from 2005 to 2008 when the mining landscape increased rapidly, reaching 188.31, which is consistent with the golden era of coal in China.

Table 5. Single land-use dynamics.

\begin{tabular}{|c|c|c|c|c|c|c|c|c|}
\hline Land Type & 2002-2005 & 2005-2008 & 2008-2011 & 2011-2014 & 2014-2017 & 2002-2008 & 2008-2017 & 2002-2017 \\
\hline Mining & 16.6 & 188.31 & 31.59 & 11.71 & 21.22 & 149.35 & 20 & 179.25 \\
\hline Town & 9.14 & 10.51 & 10.68 & 1.14 & 0.02 & 11.26 & 4.07 & 8.6 \\
\hline Grassland & 1.54 & -2.23 & -1.78 & -1.39 & -0.83 & -0.4 & -1.28 & 0.91 \\
\hline Water & -16.67 & 233.33 & -8.33 & 35.19 & -5.86 & 50 & 3.01 & 27.22 \\
\hline Road & 21.85 & 0 & 14.38 & 2.9 & 3.74 & 10.93 & 8.1 & 12.42 \\
\hline Severe Salinization & -31.22 & 153.57 & -21.34 & 120.65 & -2.3 & -10.75 & 6.12 & -3 \\
\hline Moderate Salinization & -31.96 & 235.12 & -28.68 & 116.4 & 20.02 & -11.12 & 0.05 & -4.44 \\
\hline Mild Salinization & -32.22 & 224.04 & -29.55 & 91.99 & 47.29 & -12.37 & 0.038 & -4.89 \\
\hline Total Salinization & -32.03 & 211.07 & -27.98 & 107.65 & 21.24 & -11.9 & 1.25 & -4.54 \\
\hline
\end{tabular}

\subsection{Analysis of Spatial Change and Development of Soil Salinization}

To further study the spatial variation of soil salinization in the Shengli mining area of Xilinhot, 0-3 values were assigned to four grades: non-salinization, mild salinization, moderate salinization, and severe salinization. According to Table 6, the change from light salinization to heavy salinization is defined as "development", from heavy salinization to lighter salinization is defined as "reversal", and if there is no change in salinization type, it is "stable".

Table 6. The development classification of soil salinization in the study area.

\begin{tabular}{|c|c|c|c|c|c|c|}
\hline $\begin{array}{c}\text { Extreme } \\
\text { Reversion }(-3)\end{array}$ & $\begin{array}{c}\text { Moderate } \\
\text { Reversion }(-2)\end{array}$ & $\begin{array}{l}\text { Mild Reversion } \\
\qquad(-1)\end{array}$ & Stable (0) & $\begin{array}{c}\text { Mild } \\
\text { Development (1) }\end{array}$ & $\begin{array}{c}\text { Moderate } \\
\text { Development (2) }\end{array}$ & $\begin{array}{c}\text { Extreme } \\
\text { Development (3) }\end{array}$ \\
\hline $3 \rightarrow 0$ & $\begin{array}{l}3 \rightarrow 1 \\
2 \rightarrow 0\end{array}$ & $\begin{array}{l}1 \rightarrow 0 \\
2 \rightarrow 1 \\
3 \rightarrow 2\end{array}$ & $\begin{array}{l}0 \rightarrow 0 \\
1 \rightarrow 1 \\
2 \rightarrow 2 \\
3 \rightarrow 3\end{array}$ & $\begin{array}{l}0 \rightarrow 1 \\
1 \rightarrow 2 \\
2 \rightarrow 3\end{array}$ & $\begin{array}{l}0 \rightarrow 2 \\
1 \rightarrow 3\end{array}$ & $0 \rightarrow 3$ \\
\hline
\end{tabular}

The years 2002, 2005, 2008, 2011, 2014, and 2017 were selected as the research periods of soil salinization reversal and development in the Shengli mining area of Xilinhot. According to Table 6, the development status of soil salinization in the Shengli mining area was classified, and the trend chart and radar chart of soil salinization development in the study area were obtained (Figure 5). The areas of soil salinization reversion in the Shengli mining area from 2002-2005, 2005-2008, 2008-2011, 2011-2014, 2014-2017, and 2002-2017 were $65.64 \mathrm{~km}^{2}, 1.03 \mathrm{~km}^{2}, 18.44 \mathrm{~km}^{2}, 0.9 \mathrm{~km}^{2}, 7.52 \mathrm{~km}^{2}$, and $62.33 \mathrm{~km}^{2}$, respectively, accounting for $6.43 \%, 0.10 \%, 1.81 \%, 0.09 \%, 0.74 \%$, and $6.10 \%$ of the total area, respectively. The area of soil salinization development is $0.84 \mathrm{~km}^{2}, 18.29 \mathrm{~km}^{2}, 1.75 \mathrm{~km}^{2}, 11.48 \mathrm{~km}^{2}, 14.59 \mathrm{~km}^{2}$ and $15.65 \mathrm{~km}^{2}$, respectively, accounting for $0.08 \%, 1.79 \%, 0.17 \%, 1.12 \%, 1.43 \%$, and $1.53 \%$ of the study area, respectively. The extreme reversal of soil salinization occurred in 2002-2005, and the overall situation was relatively stable. From the development and change in soil salinization from 2002 to 2017, it can be seen that the overall trend of soil salinization in the study area has been reversed in the past 15 years, and the reversal area is mainly distributed in the grassland landscape. The reason is that the prohibition of grazing in Xilinhot began in 2002, and the policy of "grazing rest in spring" was carried out when the grass returned to green, and the policy of "enclosure and grazing prohibition" was mainly implemented in regions of ecological fragility, grassland degradation, desertification, and saline-alkali [41] The development region is mainly distributed in the VI oilfield exploitation region and 
the VII abandoned railway test sites. According to the field investigation and literature review, the distribution of groundwater has changed due to the exploitation of oil, and the landform has changed due to the abandoned railway test sites, which has led to the development of salinization.

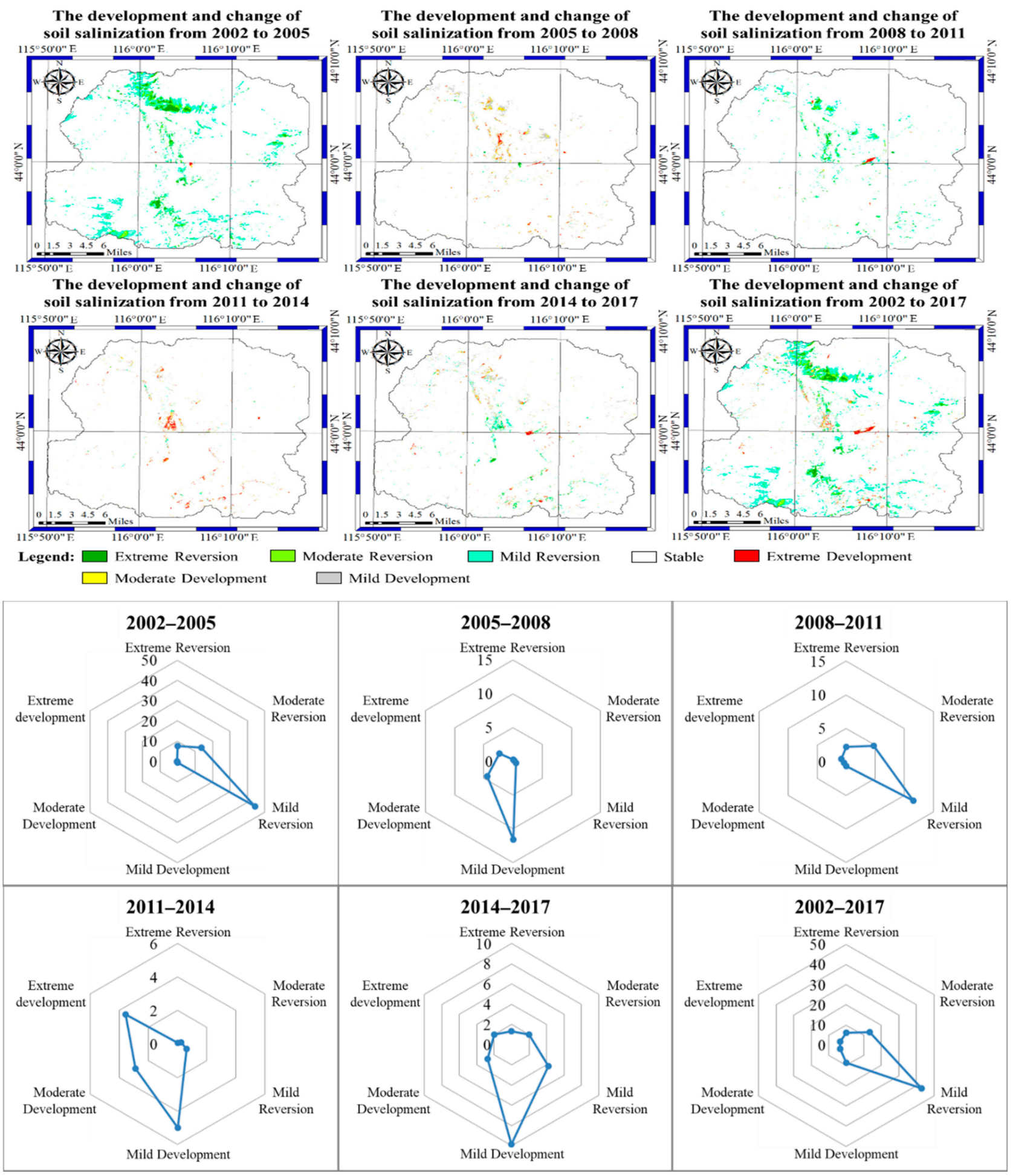

Figure 5. The development and change of soil salinization in the study area.

\subsection{Driving Force Analysis of Soil Salinization Based on Logistic Regression Model}

The years 2002, 2008, and 2017 with similar remote sensing image acquisition times were selected as the driving force analysis years of soil salinization. According to the logistic 
regression model usage conditions, the respective variables should be independent of each other. This study performed a multi-collinearity diagnosis of the respective variables, as shown in Table 7. According to the results of the first stage (2002-2008), tolerance ranged from 0.39 to 0.986 . In the second stage (2008-2017), tolerance is in the range of 0.466 to 0.994 , indicating that the multi-collinearity of the independent variables is not serious, which is suitable for the logistic regression model. The HL indicators of the two stages are 11.996 and 10.1, and their probabilities are 0.151 and 0.258 , respectively, which are not statistically significant, indicating that the logistic regression model of salinized land change fits the data well. According to Wald $\chi^{2}$ statistics and the significance level $p$, it can be seen that the driving factors of salinized land from 2002 to 2008 are in the order of distance to the nearest town landscape $>$ distance to the nearest mining landscape $>$ distance to the nearest road landscape. The driving factors of salinized land from 2008 to 2017 are in the order of distance to the nearest mining landscape $>$ distance to the nearest water landscape $>$ distance to the nearest town landscape $>$ altitude $>$ aspect.

Table 7. The correlation coefficient of the logistic regression model for soil salinization.

\begin{tabular}{|c|c|c|c|c|c|c|c|}
\hline Period & Independent Variable & $\begin{array}{c}\text { Parameter } \\
\text { Estimation }(B)\end{array}$ & $\begin{array}{l}\text { The Standard } \\
\text { Error (S.E.) }\end{array}$ & $\begin{array}{l}\text { Wald } \chi^{2} \\
\text { Statistics }\end{array}$ & $\begin{array}{c}\text { Degree of } \\
\text { Freedom }(d f)\end{array}$ & $\begin{array}{l}\text { Significance } \\
\text { Level }(p)\end{array}$ & $\begin{array}{c}\text { Occurrence Rate } \\
(O R)\end{array}$ \\
\hline \multirow{8}{*}{$\begin{array}{l}\text { The first stage } \\
\begin{array}{c}(2002-2008) \\
H L=11.996 \\
d f=8 \\
p=0.151\end{array}\end{array}$} & $\begin{array}{l}\text { Distance to nearest } \\
\text { town landscape }\end{array}$ & -0.000102 & 0.000015 & 42.241 & 1 & $<0.001$ & 0.999898 \\
\hline & $\begin{array}{l}\text { Distance to nearest } \\
\text { mining landscape }\end{array}$ & -0.000101 & 0.000016 & 41.215 & 1 & $<0.001$ & 0.999899 \\
\hline & $\begin{array}{l}\text { Distance to nearest road } \\
\text { landscape }\end{array}$ & -0.000123 & 0.000035 & 12.691 & 1 & $<0.001$ & 0.999877 \\
\hline & $\begin{array}{l}\text { Distance to nearest } \\
\text { water landscape }\end{array}$ & 0.000023 & 0.000025 & 0.845 & 1 & 0.358 & 1.000023 \\
\hline & Aspect & 0.031 & 0.023 & 1.755 & 1 & 0.185 & 1.031 \\
\hline & Slope & 0.129 & 0.079 & 2.701 & 1 & 0.1 & 1.138 \\
\hline & Altitude & -0.015 & 0.02 & 0.5652 & 1 & 0.654 & 0.986 \\
\hline & Constant & -0.44465 & 0.61911 & 0.52582 & 1 & 0.47263 & 0.64105 \\
\hline \multirow{8}{*}{$\begin{array}{c}\text { The second } \\
\text { stage } \\
(2008-2017) \\
H L=10.1 \\
d f=8 \\
p=0.258\end{array}$} & $\begin{array}{l}\text { Distance to nearest } \\
\text { town landscape }\end{array}$ & 0.000276 & 0.000052 & 27.745 & 1 & $<0.001$ & 1.000276 \\
\hline & $\begin{array}{l}\text { Distance to nearest } \\
\text { mining landscape }\end{array}$ & -0.000198 & 0.000027 & 52.666 & 1 & $<0.001$ & 0.999802 \\
\hline & $\begin{array}{c}\text { Distance to nearest road } \\
\text { landscape }\end{array}$ & -0.000112 & 0.000059 & 3.548 & 1 & 0.06 & 0.999888 \\
\hline & $\begin{array}{l}\text { Distance to nearest } \\
\text { water landscape }\end{array}$ & 0.000214 & 0.00004 & 28.098 & 1 & $<0.001$ & 1.000214 \\
\hline & Aspect & 0.054 & 0.027 & 3.908 & 1 & 0.048 & 1.056 \\
\hline & Slope & 0.033 & 0.092 & 0.127 & 1 & 0.722 & 1.033 \\
\hline & Altitude & 0.003 & 0.001 & 6.827 & 1 & 0.009 & 1.003 \\
\hline & Constant & -0.5984 & 1.40812 & 0.18059 & 1 & 0.67086 & 0.54969 \\
\hline
\end{tabular}

As a sensitive area of climate change and an increasingly active area of human disturbance, it is of great significance to study remote sensing monitoring and the driving force of soil salinization in semi-arid grassland [42]. Soil salinization is an extremely complex and dynamic process, mainly affected by human and natural factors. The natural factors leading to soil salinization over the past 15 years include topography, climate, and other factors. The study area belongs to the typical semi-arid continental climate, with little rainfall and large potential evaporation capacity, and the salt dissolved in the water accumulates easily on the soil surface. In summer, rainfall is abundant and concentrated, and a large amount of soluble salt seeps into the ground or flows away with the water. In spring, the surface water evaporates violently, and the salt in groundwater accumulates in the soil's surface with the increase in capillary water. Topography and geomorphology can also cause soil salinization. Topography directly affects the movement of surface water and groundwater, which is closely related to the movement and accumulation of salt. Water brings water-soluble salts from high places to low places and gathers in low-lying areas. Therefore, salt marshes form easily in semi-arid grassland areas (as shown in Figure 1). The human factors are mainly coal mining, overgrazing, town expansion, road construction, and other factors. In the first stage of this study, the mining of open-pit mines, town expansion, and road construction directly occupied part of the salinized land. In addition, the government's attention to regional ecological restoration also reversed the land salinization. 


\section{Conclusions}

In this study, the SMI was used to analyze soil salinization over the past 15 years:

(1) Based on six periods of remote sensing images from 2002 to 2017, the landscape pattern change characteristics of the Shengli mining area in Xilinhot City over the past 15 years were analyzed using remote sensing and GIS technology. The results demonstrated that the landscape pattern of the study area changed significantly. The grassland landscape accounted for the largest proportion (more than 74\%) of each landscape type, but the grassland landscape showed a decreasing trend year by year, while the mining landscape increased year by year. The proportion of town landscape is increasing year by year. From the perspective of the single land use dynamic degree, the mining landscape and salinized land have relatively large single land use dynamic degrees.

(2) The area of salinized land in the study area decreased from $66.36 \mathrm{~km}^{2}$ in 2002 to $21.12 \mathrm{~km}^{2}$ in 2017 , with an overall decrease of $68.17 \%$. Among these areas, salinized land changed to a mining landscape of $0.58 \mathrm{~km}^{2}$, and $95.17 \%$ of the mining landscape occupied grassland landscape; salinized land changed to a town landscape of $9.37 \mathrm{~km}^{2}$, mainly due to town expansion; salinized land turned into a road landscape of $1.81 \mathrm{~km}^{2}$, and was restored to a grassland landscape of $33.45 \mathrm{~km}^{2}$. Over the past 15 years, the salinized land in the study area showed a reverse trend.

(3) Topography, climate, town expansion, coal mining, road construction, and many other factors have a great impact on the soil salinization process in the study area. According to logistic regression analysis, the driving factors of salinized land from 2002 to 2008 are as follows: the distance to the nearest town landscape $>$ the distance to the nearest mining landscape $>$ the distance to the nearest road landscape. From 2008 to 2017, the driving factors of salinized land are as follows: the distance from the nearest mining landscape $>$ the distance to the nearest water landscape $>$ the distance to the nearest town landscape $>$ the altitude $>$ the aspect. Coal development and town expansion occupied a large area of the salinized land. Oil exploitation and abandoned railway test sites promoted the development of salinization.

(4) The SMI constructed using SI-Albedo feature space is simple and easy to calculate, which is conducive to remote sensing monitoring of salinized soil. $\mathrm{R}^{2}$ of the SMI and soil salt content of the study area in 2017 was 0.7313 , demonstrating good results from the quantitative analysis and monitoring of soil salinization in the Xilinhot Shengli Coalfield. However, through research and field investigation, it was found that the SMI based on multispectral remote sensing images is only suitable for the extraction of soil salinization information from bare land and areas with low vegetation coverage and is not suitable for areas with dense halophytes. Therefore, it is necessary to conduct an in-depth study on this issue in the future.

Author Contributions: Z.W. conceived and performed the research; M.C. and S.Z. analyzed the data; S.L. and Q.Y. provided funding support and guidance; Q.L. and L.D. revised the paper; Z.W. wrote the paper. All authors have read and agreed to the published version of the manuscript.

Funding: This research is supported by "the Fundamental Research Funds for the Central Universities 2021QN1058".

Institutional Review Board Statement: Not applicable.

Informed Consent Statement: Not applicable.

Data Availability Statement: Data is contained within the article.

Acknowledgments: The authors would like to acknowledge the China National Key R\&D and Design Project 2016YFC0501107 and the Key R\&D Plan of Inner Mongolia Autonomous Region of China 2060399-273.

Conflicts of Interest: The authors declare no conflict of interest. 


\section{References}

1. Sun, Q.; Tashpolat, T.; Ding, J.; Zhang, F.; Mamat, S.; Han, G. Study on Land Use/Cover Changes and Soil Salinization in Dry Areas: A Case Study of Shaya County in Xinjiang. Prog. Geogr. 2012, 9, 1212-1223.

2. $\quad$ Li, Y.L.; Qiao, J.F.; Dong, T.Y.; Wang, H.J. Hyperspectral inversion of soil water and salt content in soils with different textures. Chin. J. Appl. Ecol. 2016, 12, 3807-3815.

3. Jianli Ding, F.W. Environmental modeling of large-scale soil salinity information in an arid region: A case study of the low and middle altitude alluvial plain north and south of the Tianshan Mountains, Xinjiang. Acta Geogr. Sin. 2017, 1, 64-78.

4. Chengwen Chang, D.A.L. Near-infrared reflectance spectroscopic analysis of soil C and N. Soil Sci. 2002, 2, 110-116. [CrossRef]

5. Jianli Ding, Y.Y.; Wang, F. Quantitative remote sensing of soil salinization in arid regions based on three-dimensional spectrum Eigen spaces. Acta Pedol. Sin. 2013, 50, 853-861.

6. Jianli Ding, Y.Y.; Wang, F. Detecting soil salinization in arid regions using spectral feature space derived from remote sensing data. Acta Ecol. Sin. 2014, 34, 4620-4631.

7. Ding, J.; Qu, J.; Sun, Y.M.; Zhang, Y.F. The retrieval model of soil salinization information in arid region based on MSAVI-WI feature space:A case study of the delta oasis in Weigan-Kuqa watershed. Geogr. Res. 2013, 32, 223-232.

8. Fei Wang, J.D.; Manchun, W. Remote sensing monitoring models of soil salinization based in NDVI-SI feature space. Trans. Chin. Soc. Agric. Eng. 2010, 26, 168-173.

9. Zhang, T.Y.; Wang, L.; Zeng, P.L.; Wang, T.; Geng, Y.H.; Wang, H. Soil Salinization in the Irrigated Area of the Manas River Basin Based on MSAVI-SI Feature Space. Arid. Zone Res. 2016, 33, 499-505.

10. Wu, Z.; Yan, Q.; Zhang, S.; Lei, S.; Lu, Q.; Hua, X. Remote Sensing Monitoring of Soil Salinization Based on SI-Brightness Feature Space and Drivers Analysis: A Case Study of Surface Mining Areas in Semi-Arid Steppe. IEEE Access 2021, 9, 110137-110148. [CrossRef]

11. Zhang, Y.; Xiang, N.; Feng, Z. SI-Albedo space-based remote sensing synthesis index models for monitoring of soil salinization. Acta Pedol. Sin. 2009, 46, 698-703.

12. Guo, B.; Han, B.; Yang, F.; Fan, Y.; Jiang, L.; Chen, S.; Yang, W.; Gong, R.; Liang, T. Salinization information extraction model based on VI-SI feature space combinations in the Yellow River Delta based on Landsat 8 OLI image. Geomat. Nat. Hazards Risk 2019, 10, 1863-1878. [CrossRef]

13. Zeng, Y.; Feng, Z.; Xiang, N. Albedo-NDVI Space and Remote Sensing Synthesis Index Models for Desertification Monitoring. Sci. Geogr. Sin. 2006, 26, 75-81.

14. Wu, Z.; Lei, S.; Bian, Z.; Huang, J.; Zhang, Y. Study of the desertification index based on the albedo-MSAVI feature space for semi-arid steppe region. Environ. Earth Sci. 2019, 78, 232. [CrossRef]

15. Sui, X.X.; Qin, Q.M.; Dong, H.; Wang, J.L.; Meng, Q.Y.; Liu, M.C. Monitoring of Farmland Drought Based on LST-LAI Spectral Feature Space. Spectrosc. Spectr. Anal. 2013, 33, 201-205.

16. Inge Sandholt, K.R.; Jens, A. A simple interpretation of the surface temperature/vegetation index space for assessment of surface moisture status. Remote Sens. Environ. 2002, 79, 213-224. [CrossRef]

17. Xi, Y.J.W.; Feng, Y.; Jie, Z. Assessment of regional soil moisture status based on characteristics of surface temperature/vegetation index space. Acta Ecol. Sin. 2009, 29, 1205-1216.

18. Li, X.; Li, L.; Liu, X. Collaborative inversion heavy metal stress in rice by using two-dimensional spectral feature space based on HJ-1 A HSI and radarsat-2 SAR remote sensing data. Int. J. Appl. Earth Obs. Geoinf. 2019, 78, 39-52. [CrossRef]

19. Cheng, X.-J.; Xu, X.-G.; Chen, T.-E.; Yang, G.-J.; Li, Z.-H. The new method monitoring crop water content based on NIR-Red spectrum feature space. Guang Pu Xue Yu Guang Pu Fen Xi Guang Pu 2014, 34, 1542-1547.

20. Li, Y.S.; Zhao, G.X.; Wang, Z.R.; Cui, K.; Xi, X.; Dou, J.C. Remote sensing inversion of cultivated land fertility at county scale based on SWCI-NDVI feature space. Chin. J. Appl. Ecol. 2021, 32, 252-260.

21. Ronglin, T.S.W.; Yazhen, J.; Li, Z.L.; Liu, M.; Tang, B.H.; Wu, H. A review of retrieval of land surface evapotranspiration based on remotely sensed surface temperature versus vegetation index triangular/trapezoidal characteristic space. Natl. Remote Sens. Bull. 2021, 25, 65-82.

22. Yan, Q.; Huang, W.; Jin, S.; Jia, Y. Pan-tropical soil moisture mapping based on a three-layer model from CYGNSS GNSS-R data. Remote Sens. Environ. 2020, 247, 111944. [CrossRef]

23. Yan, Q.; Gong, S.; Jin, S.; Huang, W.; Zhang, C. Near Real-Time Soil Moisture in China Retrieved From CyGNSS Reflectivity. IEEE Geosci. Remote Sens. Lett. 2020, 19, 1-5. [CrossRef]

24. Guangmei Yang, Q.M.; Wenhua, L. Estimation and Enlightenment of Economic Losses due to Grassland Degradation in Xilinguole Steppe. Chin. J. Grassl. 2007, 29, 44-49.

25. Li, Y. Restoration dynamics of degraded grasslands in the typical steppe zone of Inner Mongolia. Biodivers. Sci. 1995, 03, 125-130.

26. Min, Q.; Liu, S.D.; Yang, X. Evaluation of the Ecosystem Services of the Inner Mongolia Steppe. Acta Agrestia Sin. 2004, 12, 165-169.

27. Chen, S. Land Use/Land Cover Change and Carbon Cycle in Xilin River Basin of Inner Mongolia Based on Remote Sensing and GIS; Institute of Remote Sensing Applied Technology, Chinese Academy of Sciences: Beijing, China, 2002.

28. Zou, Y. Study on the Change of Grassland in Xilinguole Supported by 3S; Inner Mongolia Normal University: Hohehot, China, 2011.

29. Wu, X. Analysis of Sand Source and its Geological Origin of Desertification in Xilinguole Grassland, Inner Mongolia; China University of Geosciences: Wuhan, China, 2018 
30. Wu, Z.; Lu, Q.; Lei, S.; Yan, Q. Study on Landscape Ecological Classification and Landscape Types Evolution: A Case Study of a Mining City in Semi-Arid Steppe. Sustainability 2021, 13, 9541. [CrossRef]

31. Wu, Z.; Lei, S.; Yan, Q.; Bian, Z.; Lu, Q. Landscape ecological network construction controlling surface coal mining effect on landscape ecology: A case study of a mining city in semi-arid steppe. Ecol. Indic. 2021, 133, 108403. [CrossRef]

32. Wu, Z.; Lei, S.; He, B.-J.; Bian, Z.; Wang, Y.; Lu, Q.; Peng, S.; Duo, L.; Duo, L. Assessment of Landscape Ecological Health: A CaseStudy of a Mining City in a Semi-Arid Steppe. Int. J. Environ. Res. Public Health 2019, 16, 752. [CrossRef]

33. Wu, Z.; Lei, S.; Lu, Q.; Bian, Z. Impacts of Large-Scale Open-Pit Coal Base on the Landscape Ecological Health of Semi-Arid Grasslands. Remote Sens. 2019, 11, 1820. [CrossRef]

34. Wu, Z.; Lei, S.; Lu, Q.; Bian, Z.; Ge, S. Spatial distribution of the impact of surface mining on the landscape ecological health of semi-arid grasslands. Ecol. Indic. 2019, 111, 105996. [CrossRef]

35. Liang, S. Narrowband to broadband conversions of land surface albedo I: Algorithms. Remote Sens. Environ. 2001, 76, 213-238. [CrossRef]

36. Nasir Mahmood Khan, Y.S. Monitoring hydro-salinity status and its impact in irrigated semi-arid areas using IRS-1B LISS-II data. Asian J. Geoinform. 2001, 1, 63-73.

37. Verstraete, M.; Pinty, B. Designing optimal spectral indexes for remote sensing applications. IEEE Trans. Geosci. Remote Sens. 1996, 34, 1254-1265. [CrossRef]

38. Xue, W. SPSS Statistical Analysis Method and Its Application; Publishing House of Electronics Industry: Beijing, China, 2013.

39. Xie, H. Driving force analysis of land use changes in the typical farming-pastoral ecotone. Trans. Chin. Soc. Agric. Eng. 2008, 10, $56-62$.

40. Jiaxing Xu, G.L.; Guoliang, C. Driving force analysis of land use change based on Logistic regression model in the mining area. Trans. Chin. Soc. Agric. Eng. 2012, 28, 247-255.

41. Xiaoguang Ni, Y.C.; Xiong, J. Reflections on the Practice of Grassland Ecological Protection and Construction in Xilin Gol League. Inn. Mong. Pratacult. 2005, 17, 6-8. [CrossRef]

42. Ding Hua, X.H. Spatiotemporal change and drivers analysis of desertification in the arid region of northwest China based on geographic detector. Environ. Chall. 2021, 4, 100082. [CrossRef] 